\title{
Analysis of MMP2 promoter polymorphisms in childhood obesity
}

\author{
Angharad R Morgan ${ }^{1,2^{*}}$, Dug Yeo Han ${ }^{1,2}$, John MD Thompson ${ }^{3}$, Edwin A Mitchell ${ }^{3}$ and Lynnette R Ferguson ${ }^{1,2}$
}

\begin{abstract}
Background: Several lines of evidence suggest a possible functional role of Matrix metalloproteinase -2 (MMP-2) in obesity. The aim of this study was to evaluate the role of MMP-2 promoter polymorphisms in percentage body fat (PBF) as a measure of childhood obesity in a New Zealand population.

Findings: 546 samples from the Auckland Birthweight Collaborative (ABC) study were genotyped for the three MMP-2 promoter SNPs -1306 C/T (rs243865), -1575G/A (rs243866) and -790 T/G (rs243864) using the Sequenom genotyping platform. The results demonstrated that an MMP-2 promoter haplotype is associated with PBF in New Zealand 7 year old children.
\end{abstract}

Conclusion: We have previously determined that environmental factors are associated with differences in PBF in this study group, and now we have demonstrated a possible genetic contribution.

Keywords: childhood obesity, percentage body fat, matrix metalloproteinase-2, genetic association

\section{Introduction}

Obesity is reaching epidemic proportions worldwide and is now occurring at younger ages. In New Zealand, one in twelve youngsters aged 2 to 14 years are considered to be obese and one in five are classified as overweight (A Portrait of Health, 2006/07 New Zealand Health Survey).

Obese children are at increased risk of a number of health problems including diabetes, sleep problems, joint problems, early puberty or menarche, asthma and other respiratory problems [1]. Obesity often persists into adulthood and is associated with increased morbidity and mortality $[2,3]$.

Body mass index (BMI) is the most common method used to determine obesity. However, although BMI may facilitate an adult obesity diagnosis, using this method to diagnose obesity in children may yield more ambiguous results, as BMI is a marker of relative weight and doesn't directly measure body fat [4]. Measuring percentage body fat (PBF) may be a more effective method of diagnosing obesity in children.

Childhood obesity is thought to be the result of an interplay between many genetic and environmental factors. We

\footnotetext{
* Correspondence: ang.morgan@auckland.ac.nz

${ }^{1}$ Discipline of Nutrition, FMHS, The University of Auckland, New Zealand Full list of author information is available at the end of the article
}

have previously investigated environmental factors in the Auckland Birthweight Collaborative (ABC) study, and found maternal overweight/obesity, maternal age, female gender, sedentary activity time and hours of television viewing to be independently associated with PBF in 7 year old children [5]. We are now interested in identifying possible genetic factors.

Several lines of evidence suggest a possible functional role of Matrix metalloproteinase -2 (MMP-2) in obesity. The main role of MMP-2 is in the degradation of type IV collagen, the major structural component of basement membranes. However, the enzyme also has activity toward a spectrum of functional molecules including growth factor-binding proteins and growth factor receptors, which are known to be involved in obesity. For example, MMP-2 can cleave insulin-like growth factor-binding proteins and release insulin-like growth factors [6]. It has also been suggested that MMP-2 plays an important role in adipose tissue development [7-10]. Furthermore, tissue degradation by MMP-2 is pivotal to inflammation [11], and obesity is associated with low grade inflammation.

We undertook an association analysis of 3 functional polymorphisms in the promoter of the MMP-2 gene $(-1306 \mathrm{C} / \mathrm{T},-1575 \mathrm{G} / \mathrm{A}$ and $-790 \mathrm{~T} / \mathrm{G})$, to investigate the possible role for MMP-2 as a genetic risk factor for obesity (in terms of increased PBF) in the $\mathrm{ABC}$ study.
C Biomed Central

C 2011 Morgan et al; licensee BioMed Central Ltd. This is an open access article distributed under the terms of the Creative Commons Attribution License (http://creativecommons.org/licenses/by/2.0), which permits unrestricted use, distribution, and reproduction in any medium, provided the original work is properly cited. 
The $-1306 \mathrm{C} / \mathrm{T}$ (rs243865) polymorphism is located in the CCACC box of the Sp1-binding site and displays a strikingly lower promoter activity with the $\mathrm{T}$ allele [12]. The $-1575 \mathrm{G} / \mathrm{A}$ (rs243866) variant is located immediately 5 ' to a half-palindromic potential oestrogen receptor binding site and the $G$ allele functions as an enhancer [13]. The -790 T/G (rs243864) SNP is located in the inverted GATA-1 element (CTATCT) in the promoter region. Three important transcription factors (GKLF-gut enriched Krueppel-like factor, S8, and Evil-ectopic viral integration site 1 encoded factor) may bind with the $\mathrm{T}$ allele but not with the G allele [14].

\section{Methods}

Participants

The ABC study was designed as a case-control study to determine risk factors for small for gestational age (SGA) infants and has been described in detail previously [15]. Data have been collected at birth, 1, 3.5, 7 and most recently 11 years of age. The original sample at birth resulted in a sample of 1714 subjects, of which 871 mothers were identified in the obstetric data to be of European ethnicity. At the age of 1 and 3.5 follow up of non-European ethnicities was poor resulting in a lack of ability to generalise the results from these children to their particular populations. As a result follow-up from the age of 7 has only been carried out on those children whose mothers were identified as European ethnicity at birth.

Percentage body fat (PBF) at age 7 years was the outcome measure analysed in this paper. This was measured using bioelectrical impedance analysis (BIA). This allows calculation of fat free mass which was calculated according to the formula of Schaeffer et al [16] and consequently percentage body fat.

At 11 years 546 participants consented to collection of peripheral blood $(n=397)$ or a buccal swab $(n=149)$ for DNA extraction and genotyping.

\section{Genotyping}

DNA was extracted from the blood/buccal samples using Qiagen's DNA extraction kit and following the manufacturer's instructions. Genotyping was performed with the MassARRAY and iPlex systems of the Sequenom genotyping platform (Sequenom, San Diego, CA), which uses the MALDI-TOF primer extension assay $[17,18]$, according to manufacturers' recommendations. The SNPs were in a multiplex with SNPs from a different study that used the same samples. Assays were optimized in 24 samples consisting of 20 reference Centre d'Etude du Polymorphisme Humain (CEPH) samples and 4 blanks. All sample plates contained cases, controls, blanks, CEPH and duplicate samples. Quality control measures included independent double genotyping, blind to sample identity and blind to the other caller, and comparison of our CEPH genotypes to those in the HapMap http://www.hapmap.org.

\section{Statistical analysis}

SNPs were tested for deviation from Hardy-Weinberg equilibrium (HWE) using a chi-square goodness-of-fit test.

A Generalised linear model (GLM) was used to test the linearity of genotype-phenotype relationship for quantitative traits. For linearity of the genotype-phenotype relationship for quantitative traits, each SNP was coded 0,1 , and 2 for each tested allele [19,20]. For example, G/G, G/T, and T/T were coded as 0,1 , and 2 for the $\mathrm{T}$ allele for rs243864. All analyses were controlled for SGA status due to the disproportionate sample of SGA and AGA at birth (phase 1). Multivariable analyses also controlled for environmental factors previously shown to be independently related in this dataset to PBF namely sex of the child, maternal body mass index, maternal age at the birth of the child, hours of television watched per day, and the amount of time spent in sedentary activities [5].

To determine LD (linkage disequilibrium) between the SNPs we uploaded our data into haploview [21]. Haplotype blocks were defined using the default algorithm which uses confidence intervals [22]. Haplotype analysis was carried out using HAPLO.SCORE in $\mathrm{R}$ to test for association of the haplotypes with PBF.

Statistical analyses were carried out using $\mathrm{R}$ [23] and SAS (V9.1 SAS Institute., Cary, NC, USA). A p-value less than 0.05 was considered statistically significant.

\section{Ethical approval}

The study received ethical approval from the Northern Regional Ethics Committee. Signed consent for the study and extraction of DNA was given by the parents of the children and assent also given by the child.

\section{Results}

The genotype counts (frequencies) for the three genotyped SNPs are shown in table 1. Each of the SNPs met Hardy Weinberg criteria. All 3 SNPs were found to be associated with PBF (table 2). The T allele of rs243864, the $C$ allele of rs 243865 and the $G$ allele of rs 243866 were associated with a higher $\mathrm{PBF}$ as compared to the alleles G, T and A respectively. However, the results just

\begin{tabular}{|c|c|c|c|}
\hline rs243866: & $\mathrm{AA}=31(0.060)$ & $A G=191(0.350)$ & $\mathrm{GG}=305(0.590)$ \\
\hline rs243865: & $\Pi=34(0.066)$ & $C T=179(0.347)$ & $C C=303(0.587)$ \\
\hline rs243864: & $G G=33(0.063)$ & $\mathrm{GT}=185(0.350)$ & $\Pi=310(0.587)$ \\
\hline
\end{tabular}


Table 2 Effect of MMP2 promoter SNPs on PBF

\begin{tabular}{cccc}
\hline SNP & Tested allele & Estimate $(\mathbf{9 5 \%} \mathrm{Cl})$ & $\mathbf{p}$ \\
\hline rs243864 & $\mathrm{T}$ & $1.32(0.08-2.56)$ & $\mathbf{0 . 0 3 7}$ \\
rs243865 & $\mathrm{C}$ & $1.40(0.16-2.64)$ & $\mathbf{0 . 0 2 7}$ \\
rs243866 & $\mathrm{G}$ & $1.42(0.16-2.69)$ & $\mathbf{0 . 0 2 8}$ \\
\hline
\end{tabular}

fell below statistical significance after adjustment for environmental factors previously shown to be independently related in this dataset to PBF: sex of the child, maternal body mass index, maternal age at the birth of the child, hours of television watched per day, and the amount of time spent in sedentary activities [5] (table $3)$. The SNPs were not associated with any of the confounding factors (data not shown, but available on request).

The 3 MMP-2 promoter SNPs are in high LD with each other (Figure 1), so we undertook haplotype analysis. The GTA (rs243864, rs243865, and 243866 respectively) haplotype was significantly associated with PBF $(\mathrm{p}=0.019)$. Individuals with the GTA haplotype had lower PBF in comparison to individuals with the TCG haplotype (table 4). After adjustment for confounding factors, the GTA haplotype remained significantly associated with PBF ( $\mathrm{p}=0.040)$ (table 5).

\section{Discussion}

This paper reports for the first time the role of MMP-2 promoter polymorphisms in childhood obesity as measured using PBF. Although we were unable to demonstrate an association for the 3 SNPs individually after correcting for confounding factors, the GTA (rs243864, rs243865, 243866) haplotype was statistically significant. It has previously been suggested that studying haplotypes could be more informative than the study of individual SNPs [24,25].

Genetic variation in MMP-2 has been previously investigated for association with obesity, in adults from Korea [26]. Whereas we have focussed on promoter SNPs and PBF, Han et al. investigated coding SNPs and looked for association with BMI. They found 2 SNPs (out of the 5 investigated) to be associated with overweight/obesity, and also identified a haplotype as significant. Taken together with our own results, it can be concluded that MMP-2 may be an important susceptibility gene for obesity in both children and adults.

Table 3 Effect of MMP2 promoter SNPs on PBF after adjustment for confounding factors

\begin{tabular}{cccc}
\hline SNP & Tested allele & Estimate $(\mathbf{9 5 \%}$ CI) & p \\
\hline rs243864 & $T$ & $0.990(-0.19-2.17)$ & 0.099 \\
rs243865 & $\mathrm{C}$ & $1.144(-0.03-2.31)$ & 0.055 \\
rs243866 & $\mathrm{G}$ & $1.164(-0.03-2.36)$ & 0.057 \\
\hline
\end{tabular}

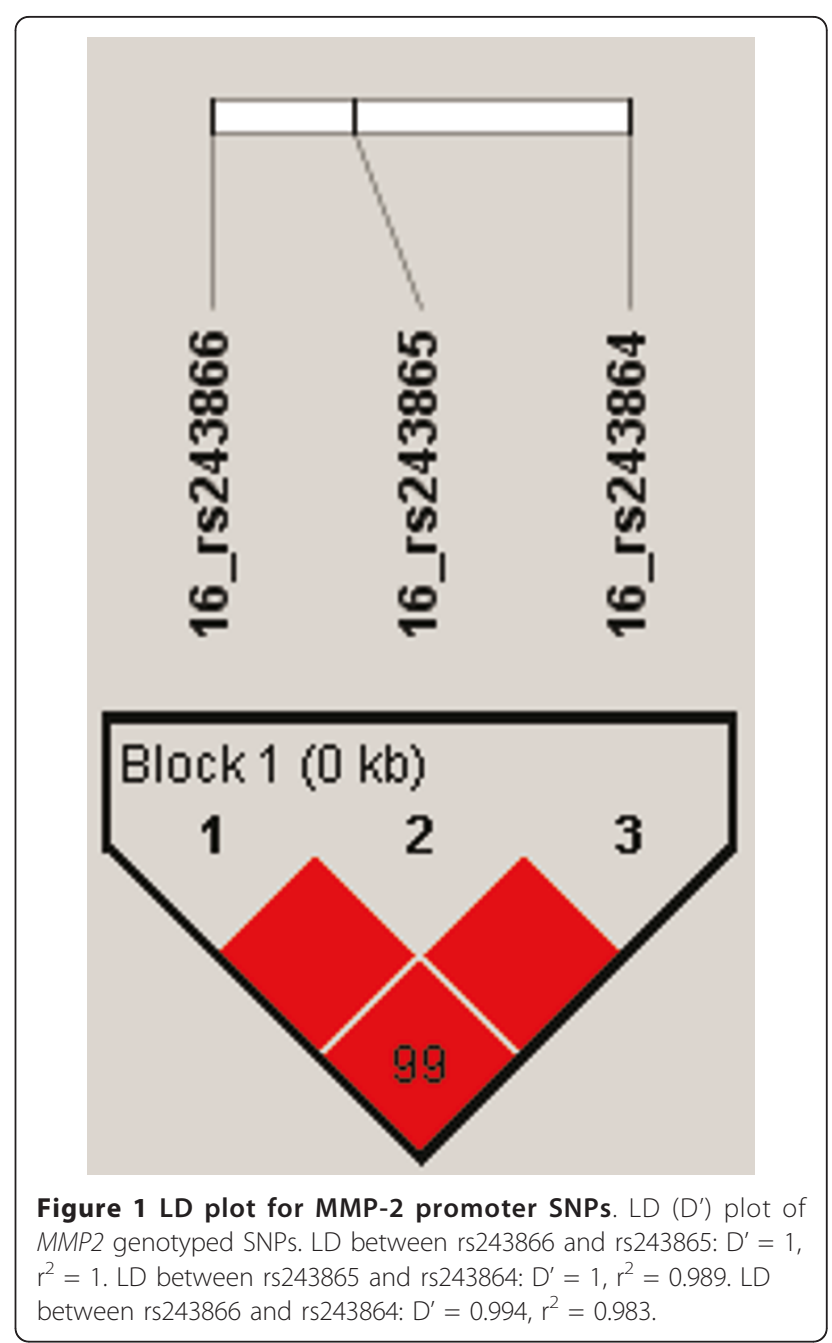

The genetic association we report in the MMP-2 promoter may result from altered MMP expression, as the 3 SNPs investigated are all functional SNPs capable of affecting transcriptional activity. Indeed, associations with MMP-2 circulating levels in mouse models and obese children and adults have been previously reported. High expression of MMP-2 has been demonstrated in adipose tissue of mice with nutritionally induced obesity, as well as in genetically obese mice $[9,10,27]$. Bouloumiè et al. [8] provided the first evidence that human adipose

Table 4 Haplotype analysis

\begin{tabular}{|c|c|c|c|c|c|c|c|}
\hline & rs243864 & rs243865 & rs243866 & $\begin{array}{l}\text { hap. } \\
\text { freq }\end{array}$ & coef & se & $p$ \\
\hline haplo.base & $\mathrm{T}$ & C & G & 0.766 & 23.63 & 0.71 & \\
\hline mmp2hap.1 & G & $\mathrm{T}$ & A & 0.231 & -1.56 & 0.66 & 0.019 \\
\hline $\begin{array}{l}\text { mmp2hap. } \\
\text { rare }\end{array}$ & * & * & $*$ & 0.003 & 2.11 & 5.62 & 0.708 \\
\hline $\begin{array}{l}\text { centileNT } \\
\text { (AGA) }\end{array}$ & & & & & 2.65 & 0.82 & 0.001 \\
\hline
\end{tabular}


Table 5 Haplotype analysis after adjustment for confounding factors

\begin{tabular}{lcccccccc}
\hline & rs243864 & rs243865 & rs243866 & $\begin{array}{c}\text { hap. coef } \\
\text { freq }\end{array}$ & se & p \\
\hline haplo.base & $T$ & C & $G$ & 0.766 & & & \\
mmp2hap.1 & $G$ & $T$ & $A$ & 0.232 & -1.30 & 0.63 & $\mathbf{0 . 0 4 0}$ \\
mmp2hap. & $*$ & $*$ & $*$ & 0.003 & 3.17 & 5.33 & 0.553 \\
rare & & & & & & & & \\
\hline
\end{tabular}

tissue releases MMP-2. Later two studies by the same group described decreased circulating levels of MMP-2 (and increased levels of MMP-9 and TIMP-1) in obese children $[28,29]$. Whilst a study examining obesity in adults demonstrated increased MMP-2 (and MMP-9) levels [30].

Additional studies are now required to further investigate MMP-2 involvement in the development of obesity. It may be also be worth considering other matrix metalloproteinases.

In conclusion the results presented here demonstrate that an MMP-2 promoter haplotype is associated with PBF in New Zealand 7 year old children. We have previously determined that environmental factors are associated with differences in PBF in the ABC study, and now we have demonstrated a possible genetic contribution.

\section{Acknowledgements}

The initial study was funded by the Health Research Council of New Zealand. The 12 month postal questionnaire was funded by Hawkes Bay Medical Research Foundation. The 3.5 year follow-up study was funded by Child Health Research Foundation, Becroft Foundation and Auckland Medical Research Foundation. The 7 year follow-up study was funded by Child Health Research Foundation. The 11 year follow-up was funded by Child Health Research Foundation and the Heart Foundation. The genetic component of this study was funded by Child Health Research Foundation. We acknowledge the assistance of Gail Gillies, Barbara Rotherham and Helen Nagels for contacting or assessing the participants. We sincerely thank the parents and children for participating in this study. The assessments of the children were conducted mainly in the Starship Children's Research Centre that is supported by the Starship Foundation and Auckland HealthCare Ltd. EA Mitchell and JMD Thompson are supported by the Child Health Research Foundation. AR Morgan, DY Han and LR Ferguson are supported by Nutrigenomics New Zealand which is collaboration between AgResearch Ltd., Plant \& Food Research and The University of Auckland with funding through the Foundation for Research Science and Technology.

\section{Author details}

'Discipline of Nutrition, FMHS, The University of Auckland, New Zealand. ${ }^{2}$ Nutrigenomics New Zealand, New Zealand. ${ }^{3}$ Department of Paediatrics, FMHS, The University of Auckland, New Zealand.

\section{Authors' contributions}

ARM made substantial contributions to this study. She designed the study, carried out the genotyping experiments and was primary author of the manuscript. DYH was responsible for the statistical analysis. JMDT helped in establishing the $A B C$ cohort and its data collection and contributed to editing of the manuscript. EAM established the ABC cohort and its data collection and contributed to editing of the manuscript. LRF participated in editing of the manuscript. All authors read and approved the final manuscript.

\section{Competing interests}

The authors declare that they have no competing interests.
Received: 9 February 2011 Accepted: 21 July 2011

Published: 21 July 2011

\section{References}

1. Lee YS: Consequences of childhood obesity. Ann Acad Med Singapore 2009, 38(1):75-77.

2. Whitaker RC, Wright JA, Pepe MS, et al: Predicting obesity in young adulthood from childhood and parental obesity. N Engl J Med 1997 337:869-873

3. Micić D: Obesity in children and adolescents-a new epidemic? Consequences in adult life. J Pediatr Endocrinol Metab 2001, 14(Suppl 5):1345-1352.

4. Hall DM, Cole TJ: What use is the BMI? Arch Dis Child 2006, 91:283-286.

5. Blair NJ, Thompson JMD, Black PN, et al: Risk factors for obesity in 7-yearold European children: the Auckland Birthweight Collaborative Study. Arch Dis Child 2007, 92(10):866-871.

6. Sternlicht MD, Werb Z: Matrix metalloproteinase. In Guidebook to the extracellular matrix, anchor and adhesion proteins. Edited by: Kreis T, Vale R. Oxford University Press New York; 1999:503-603.

7. Brown LM, Fox HL, Hazen SA, et al: Role of the matrixin MMP-2 in multicellular organization of adipocytes cultured in basement membrane components. Am J Physiol 272(3 Pt 1):C937-49.

8. Bouloumié $A$, Sengenès $C$, Portolan $G$, et al: Adipocyte produces matrix metalloproteinases 2 and 9: involvement in adipose differentiation. Diabetes 2001, 50:2080-2086.

9. Lijnen HR: Plasmin and matrix metalloproteinases in vascular remodelling. Thrombosis and Haemostasis 2001, 86:324-333.

10. Lijnen HR, Maquoi E, Demeulemeester $\mathrm{D}$, et al: Modulation of fibrinolytic and gelatinolytic activity during adipose tissue development in a mouse model of nutritionally induced obesity. Thrombosis and Haemostasis 2002, 88:345-353.

11. Lagente V, Boichot E: Matrix Metalloproteinases in Tissue Remodelling and Inflammation (Progress in Inflammation Research). 2008, 1-168.

12. Price SJ, Greaves DR, Watkins H: Identification of novel, functional genetic variants in the human matrix metalloproteinase-2 gene: role of Sp1 in allele-specific transcriptional regulation. J Biol Chem 2001, 276:7549-7558.

13. Harendza S, Lovett DH, Panzer U, et al: Linked common polymorphisms in the gelatinase a promoter are associated with diminished transcriptional response to estrogen and genetic fitness. J Biol Chem 2003, 278:20490-20499.

14. Vasku A, Goldbergova M, lzakovicova Holla L, et al: A haplotype constituted of four MMP-2 promoter polymorphisms (-1575G/A, -1306C/ $\mathrm{T},-790 \mathrm{~T} / \mathrm{G}$ and $-735 \mathrm{C} / \mathrm{T}$ ) is associated with coronary triple-vessel disease. Matrix Biol 2004, 22:585-591.

15. Thompson JM, Clark PM, Robinson E, et al: Risk factors for small-forgestational-age babies: The Auckland Birthweight Collaborative Study. J Paediatr Child Health 2001, 37(4):369-375.

16. Schaefer F, Georgi M, Zieger A, Schärer K: Usefulness of bioelectric impedance and skinfold measurements in predicting fat-free mass derived from total body potassium in children. Pediatr Res 1994, 35(5):617-624.

17. Jurinke $C$, van der Boom D, Cantor CR, et al: The use of massARRAY technology for high throughput genotyping. Adv. Biochem. Eng. Biotechnol 2002, 77:57-74.

18. Storm N, Darnhofer-Patel B, van der Boom D, et al: MALDI-TOF mass spectrometry-based SNP genotyping. Methods Molecular Biology 2003, 212:241-262.

19. Balding DJ: A tutorial on statistical methods for population association studies. Nat Rev Genet 2006, 7(10):781-791.

20. Cordell HJ, Clayton DG: Genetic association studies. Lancet 2005, 366:1121-1131.

21. Barrett JC, Fry B, Maller J, Daly MJ: Haploview: analysis and visualization of LD and haplotype maps. Bioinformatics 2005, 21(2):263-265.

22. Gabriel SB, Schaffner SF, Nguyen H, Moore JM, Roy J, Blumenstiel B, et al: The structure of haplotype blocks in the human genome. Science 2002, 296(5576):2225-2229.

23. Ihaka R, Gentleman R: R: A language for data analysis and graphics. Journal of Computational \& Graphical Statistics 1996, 5(3):299-314.

24. Ober C, Leavitt SA, Tsalenko A, et al: Variation in the interleukin 4-receptor alpha gene confers susceptibility to asthma and atopy in ethnically diverse populations. Am J Hum Genet 2000, 66:517-526. 
25. Bottini $\mathrm{N}$, Borgiani $\mathrm{P}$, Otsu $\mathrm{A}$, et al: IL-4 receptor alpha chain genetic polymorphism and total lgE levels in the English population: two-locus haplotypes are more informative than individual SNPs. Clin Genet 2002, 61:288-292.

26. Han DH, Kim SK, Kang S, et al: Matrix Metallopeptidase 2 Gene Polymorphism is Associated with Obesity in Korean Population. Korean J Physiol Pharmacol 2008, 12(3):125-129.

27. Van Hul M, Lijnen HR: A functional role of gelatinase $A$ in the development of nutritionally induced obesity in mice. J Thromb Haemost 2008, 6(7):1198-206.

28. Glowinska-Olszewska B, Urban M, Florys B: Selected matrix metalloproteinases (MMP-2 and MMP-9) in obese children and adolescents. Endokrynol Diabetol Chor Przemiany Materii Wieku Rozw 2006, 12:179-183.

29. Glowinska-Olszewska B, Urban M: Elevated matrix metalloproteinase 9 and tissue inhibitor of metalloproteinase 1 in obese children and adolescents. Metabolism 2007, 56:799-805.

30. Derosa G, Ferrari I, D'Angelo A, et al: Matrix metalloproteinase-2 and -9 levels in obese patients. Endothelium 2008, 15(4):219-224.

doi:10.1186/1756-0500-4-253

Cite this article as: Morgan et al: Analysis of MMP2 promoter polymorphisms in childhood obesity. BMC Research Notes 2011 4:253.

\section{Submit your next manuscript to BioMed Central} and take full advantage of:

- Convenient online submission

- Thorough peer review

- No space constraints or color figure charges

- Immediate publication on acceptance

- Inclusion in PubMed, CAS, Scopus and Google Scholar

- Research which is freely available for redistribution

Submit your manuscript at www.biomedcentral.com/submit 